\title{
AN APPROACH OF VICARIOUS CALIBRATION OF SENTINEL-2 SATELLITE MULTISPECTRAL IMAGE BASED ON SPECTRAL LIBRARY FOR MAPPING OIL SPILLS
}

\author{
Jamal Jasim Abdulla Althawadi ${ }^{1,2}$, Mazlan Hashim ${ }^{1,2, *}$ \\ ${ }^{1}$ Faculty of Built Environment \& Surveying, Universiti Teknologi Malaysia, 81310 UTM Johor Bahru, Johor, MALAYSIA. \\ jamjam144@hotmail.com \\ ${ }^{2}$ Geoscience \& Digital Earth Centre, Reasearch Institute for Sustainable Environment (RISE), \\ Universiti Teknologi Malaysia, 81310 UTM Johor Bahru, Malaysia \\ mazlanhashim@utm.my
}

KEY WORDS: Oil spills, Spectral signatures, calibration, variants, Sentinel-2 MSI

\begin{abstract}
:
Sentinel-2 satellite Multispectral Image (MSI) is one of the recent advancement of satellite optical imaging for detecting and tracking oil spills. MSI equipped with enhanced radiometric and spatial resolutions, apart from relatively high temporal resolution of every 5 days revisit capability. Both systematic errors of the geometric and radiometric of level 1 and 2 data were successfully treated before any data download for users' levels applications. As such, leaving the random errors, crucially to be minimized to enable oil spill detection and tracking due to non-discernible absolute signatures of spills against the scene background and the look-alikes. The magnitude of these random errors' minimization and the efficacy of the MSI absolute signatures within visible bands for oil spills is very crucial. However, it is rarely reported; in fact, it is a new issue to be addressed accordingly. The calibrating tool was created with oil spill spots revealed by the official authorities. Whereas, the spill pixels are identified in the corresponding pre-processed Sentinel MSI image using region growing segmentation algorithm. These spill pixels grown were analyzed against the RGB bands, logistically regressed against the oil spill via a spectral library of the crude oil type. Originated from Arabian Gulf region with an average film thickness of 0.5 to $4 \mathrm{~mm}$; reporting a calibrating function in a form gain and bias corrections for RGB bands, respectively. The results indicated that calibrated MSI spill pixels have higher correlation ( $\mathrm{r} 2>0.85, \mathrm{p}<0.001)$. As the signature variations were used to formulate calibration matrices for spills identified from satellite images which can be used for processing of spill monitoring system.
\end{abstract}

\section{INTRODUCTION}

Ssatellite-based oil spills detection and tracking have undergone remarkable advances. As the most significant of these studies, range from the visible, shortwave to thermal infrared (optical) and the microwave radar bands. The ability to characterize the uniqueness emanating from the interactions of incident energy on spills are the critical elements in detecting the spill in both optical and radar bands. The sea/ocean surfaces conditions and the corresponding local weather systems produce significant variations in resultant signatures of spills. The differences within the signature of the spill cause high uncertainties in delineating between spills and look-alikes. Researchers have focused their studies on detection and mapping spills against the background (Garcia-Pineda et al., 2017; Mullin, 2017; Topouzelis, 2008).

Recent occurrence starts at the time of spills, the characteristics of its viscosity and floating of the spill above the water surface, depends on the volume and the surrounding environmental factors such as wind velocity. Previous studies of Cheng et al. (2011); Guo, (2017) and Spaulding, (2017) used models to address environmental dynamics of spills. However, they did not address the characteristics of the spill signatures interactions within the environment. Extracting oil spill signatures using remote sensing (RS) is a continuous process and an evergreen study (Bhangale et al., 2017; Fiscella et al., 2000). This article highlights a calibration tool-encompassing matrix for treating the red, green, and blue (RGB) bands of MSI within visible wavelength for minimization of random errors. The minimization of the errors was done in the scene local environment of the Arabian Gulf (AG) region. Reliable statistics on the level and current distributions of oil pollution are missing. However, available data and information show that the Gulf region has high levels of oil and hydrocarbon pollution because of deliberately and accidentally discharge of oil and oilrelated effluents (Gawad et al. 2008, Gevao et al. 2006).

In calibrating spectral data from satellite-based remotely sensed data, they are two commonly used techniques such as the vicarious and the air-to-ground correlation. The first approach requires a stable target to be pre-installed before acquiring any satellite data. While the other method requires in-situ radiometric measurements to performed simultaneously at the time of satellite data acquisitions. However, in the case of oil spills occurrence, both calibration approaches are impractical, as the satellite data acquisitions rarely coincide from start to diminishing-end of spills. These are derived from the seasurface due to dynamic characteristics of the sea.

Consequently, this article introduces a calibration approach for oil spills using the vicarious based-method with the input of oil spill spectral library. The control-based average spectral observations of oil spill film thickness from $0.25 \mathrm{~mm}$ to $4 \mathrm{~mm}$ (Clark et al. 2010) were used as a reference in calibrating identified from pre-processed satellite data. The hypothesis in this study assumed that the approach could improve the detectability of spills. 


\section{MATERIALS AND METHOD}

\subsection{Study Area}

The study area is conducted in the Arabian Gulf, Located between the Arabian Peninsula and south-western Iran (Figure 1). They are covering a sea area of about $241,000 \mathrm{~km}^{2}$ with 990 $\mathrm{km}$ total length and width range from $55 \mathrm{~km}$ to $340 \mathrm{~km}$ (Powers et al., 1966). It boarded by several countries, including Kuwait, Saudi Arabia, Bahrain, Qatar, United Arab Emirates, Iraq, Oman, and Iran. The spills considered in this study occurred between January 2016 to January 2018. The spill records were compiled by the Marine Emergency Mutual Aid Centre (MEMAC). Seven major spill locations designated as A to $G$ were used, as shown in Figure 1. Sentinel-2 MSI satellite images were extracted from each site to show the area of the spill. Spill areas ranged from $800-50,000$ pixels in area. They were of various shapes mostly influenced by local wind and current conditions.

\begin{tabular}{llll}
\hline Location & $\begin{array}{l}\text { Date of } \\
\text { spill }\end{array}$ & $\begin{array}{l}\text { Sentinel-2 } \\
\text { MSI }\end{array}$ & $\begin{array}{l}\text { Path/row } \\
\text { MSI }\end{array}$ \\
\hline Al-Khafji & $9 / 5 / 2016$ & $17 / 7 / 2016$ & $204 / 010$ \\
Iran & $9 / 10 / 2016$ & $12 / 10 / 2016$ & $204 / 006$ \\
Zour & $10 / 8 / 2017$ & $11 / 8 / 2017$ & $205 / 006$ \\
Darius & $8 / 8 / 2017$ & $11 / 8 / 2017$ & $203 / 005$ \\
Al-Arabiyah & $26 / 9 / 2017$ & $30 / 9 / 2017$ & $207 / 009$ \\
Safa Oilfield & $25 / 8 / 2017$ & $28 / 8 / 2017$ & $205 / 106$ \\
Sirri Island & $7 / 9 / 2017$ & $14 / 9 / 2017$ & $208 / 014$ \\
\hline
\end{tabular}

Table 1. Date of satellite imagery used for oil detection in Arabian Gulf

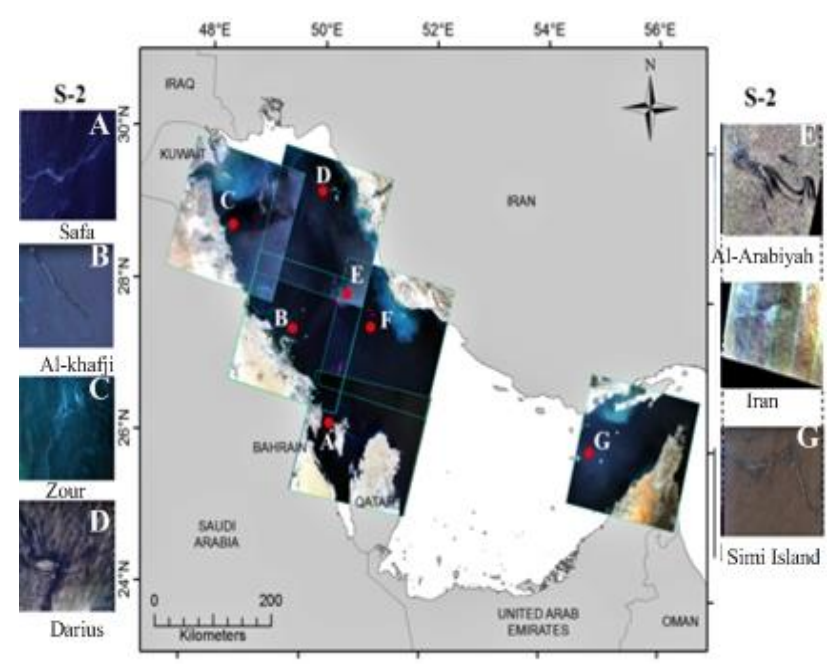

Figure 1. Study area - oil spills occurrences 2016-2017

\subsection{Satellite Data Acquisition}

The Sentinel-2 MSI data were used in this study; acquired during spill occurrences as indicated in Table 1. The sea-truths for oil spill occurrences records were obtained from the records of maritime notices and costal authorities of the area (MEMAC).

\subsection{Satellite Data Processing}

All the satellite data sets were subjected to data pre-processing comprising of the radiometric (including atmospheric) and geometric corrections. For the radiometric correction of MSI data, systematic radiometric have been conducted at various levels in this study. It started from level $1 \mathrm{~B}$ before succeeding to level 1C. The 1B systematic processing of MS2 is elaborated in the related url (https://sentinel.esa.int/web/sentinel/userguides/sentinel-2-msi/processing-levels/level-1).

The above radiometric corrections have systematically addressed the dark signal correction, pixel response nonuniformity correction, crosstalk correction, defective pixels identification, high spatial resolution bands restoration (deconvolution and de-noising), and binning of the $60 \mathrm{~m}$ spectral bands.

The atmospheric correction is complemented in this study for minimisation of scattering effects on adjacent pixels, which was performed on all the images set. The algorithm of the atmospheric correction for the entire spectral bands of images was realised via the FLAASH program of the ENVI.Version5 software, where its theoretical basis is given in equation 1.

$$
L i=\left(\frac{A_{\rho}}{1-\rho_{e} S}\right)+\left(\frac{B \rho_{e}}{1-\rho_{e} S}\right)+L_{a}
$$

where:

$\mathrm{Li}=$ the spectral radiance at sensor pixel;

$\rho=$ the pixel surface reflectance;

$\rho e=$ an average surface reflectance for the pixel and a surrounding region;

$\mathrm{S}=$ the spherical albedo of the atmosphere;

$\mathrm{La}=$ the radiance back scattered by the atmosphere; and

$\mathrm{A}$ and $\mathrm{B}=$ coefficients that depend on atmospheric and geometric conditions but not on the surface.

After the atmospheric correction, the DN conversion was performed by dividing each spectral band (visible bands) with absolute 10000 to obtain reflectance unit (Lantzanakis et al., 2017). This unit was attained on each pixel, of the Sentinel-2 MSI data (Toming et al., 2016).

The MSI image set was geo-referenced to the corresponding local mapping system employing the Universal Transverse Mercator coordinate system, datum WGS- 84 zone $48 \mathrm{~N}$. This geo-referenced is achieved using a set of ground control points (GCP) identifiable both in the satellite and corresponding maps of the area. Digital map of the study area was used as a reference to correct the geometric distortion of both images. A sentinel threshold value of +0.5 pixel or less was enforced in the geometric correction error. Hence ensuring all images used were accurately registered to the corresponding map of the area. The resampling scheme of nearest neighbour was selected to convert all pixel brightness recorded in digital number (DN) from data sets used to ensure minimum radiometric changes.

Image subset and image masking were performed to reduce all geometrically corrected data sets focussed to the spill-windows of interest, as shown in Figure 1, where the enlarged windows are shown in Figure 3. 


\subsubsection{Spill Pixels Identification and Extraction}

The oil spill features were identified and extracted, using the relevant signature analysis carried out in the data processing stage.

The spill signatures within the spectral band were determined by extracting all spill pixels using known reported occurrences and band feature extraction from all the respective bands. In this study, emphasis has been set to visible region - blue, green, and red bands. As previous studies on spills mainly focussed on utilising near infrared (Clark et al., 2010; Etellisi and Deng, 2012; De Carolis et al., 2012), thermal infrared (Chenault, et al., 2016; Pinel, et al., 2015; Shih \& Andrews, 2008), and radar (Setiawan, et al., 2017; De Dominicis et al., 2013; Gade, et al., 2016).

The oil spill pixels were extracted based on feature-based approach employing the region-based segmentation technique in ENVI. The extraction of all spill pixels is by initiating seed points to identify the locations of a spill of the respective 7 sites. The generated spill areas are shown in the inset of Figure 1 (A - G), whereas, a summary of the spill's area were presented in Table 2.

\begin{tabular}{lll}
\hline Location & Sentinel-2 MSI & \\
\hline & Total pixel & $\mathrm{km} 2$ \\
\hline Iran & 167,317 & 16.73 \\
Al-Arabiyah & 559,343 & 55.93 \\
Zour & 73,753 & 7.38 \\
Darius & 101,877 & 10.19 \\
Alkhafji & 64,594 & 6.46 \\
Safa & 33,285 & 3.33 \\
Sirri & 72,450 & 7.25 \\
\hline
\end{tabular}

Table 2. Summary of spills identified based on regions grown

\subsubsection{Calibration of Sentinel-2 MSI bands for spill pixels}

The signatures of the spills from all the visible bands of the satellite image sets were grouped into 3 major spectral visible regions of red $(\mathrm{R})$, green $(\mathrm{G})$ and blue $(\mathrm{B})$ - the average of each spill events extracted from all the signatures for each of 7 spill occurrence locations.

The signatures RGB spectral bands were plotted against the corresponding spectral responses record of oil slick film over seawater from the reference library (Clark et al., 2010). Figure 2 shows the variations of the Sentinel2 MSI against the corresponding spectral reference library, marked as in-situ reflectance. Regressing the means of the RGB signatures from all the 7 sites in the Arabian Gulf region against the spectral reference were realised (see Figure 2). The regression showed that there are still variations of random errors inherent in both systematically and randomly (atmospherically) MSI corrected bands. This regression function generated were used for calibration function applied deductively for all the respective RGB bands of the 7 sites.

Figure 2. Calibration function generated by regression of the pre-processed Sentinel-2 MSI data set against reference spectra of the spill in RGB bands. Means of spill signatures from 7 location spill occurrences at a significance level, $p<0.001$.
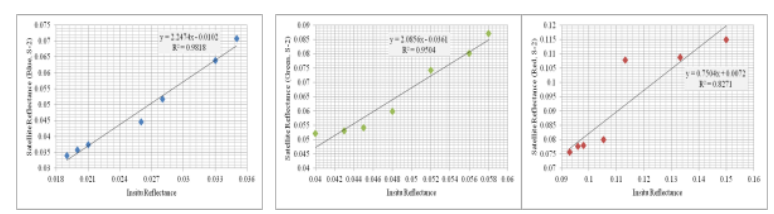

Figure 2. Variations of means-of-spill signatures from 7 occurrences against spill signatures of NASA (Clark, et al., 2010). Signatures of Sentinel-2 MSI represents in blue, green and red spectral regions

\section{RESULTS AND DISCUSIÓN}

The calibrated function created using the spectral reference and the pre-processed MSI data sets shown proper consistency, with $\mathrm{R}^{2}$ of 0.820 .95 to 0.98 at a significant level of $<0.001$ for red, green and blue bands, respectively. These consistencies within MSI visible bands are expected due to the finer spatial resolution of data set where depicting finer detailed spills were superbly noted.

Further analyses on the spectral regions, shows a clear indication of consistencies in the processed satellite-derived signatures. The blue signatures showed more variants compared to green and red (see Figure 3 - insets of calibrated against noncalibrated bands). The calibrated bands have shown undoubtedly the more spill variations intricateness of the interaction between the incoming solar radiation and the surface targets (spills, and water surface background). Scattering effects were also higher theoretically within the blue spectral region compared to green, and red. However, in the case, Sentinel-2 MSI of the Arabian Gulf, this study showed that the variation in red, green, and blue as observed with $\mathrm{R}^{2}$ is really consistency $\left(\mathrm{R}^{2}\right.$ range of $\left.0.86 \sim 0.98 ; \mathrm{p}<0.001\right)$. The result has, therefore, contribution significantly in reporting the absolute oil spill signatures within visible bands for the region (Arabian Gulf).

However, the on-going works included the entire spectral region such as near infra-red and thermal infrared regions. Without these absolute signatures indicators of the spill, a monitoring spill system would be based on relative analysis, which is risky in reporting the look-alikes. The calibration approach of the RGB based on lab-generated pre-processed data have addressed the systematic (at vendor scale with the $1 \mathrm{C}$ data level) and random minimisation errors. This exercise was done to view the atmospheric conditions at the data acquisition time. Ultimately, this study derived a spills calibration matrix from the calibration functions for Arabian Gulf Region for RGB bands of Sentinel-2 MSI as:

$$
\left[\begin{array}{l}
R_{\text {MSI }} \\
G_{\text {MSI }} \\
B_{\text {MSI }}
\end{array}\right]_{=}\left[\begin{array}{lll}
R_{i} & G_{i} & B_{i}
\end{array}\right] \cdot\left[\begin{array}{l}
0.7504 \\
2.0856 \\
2.2474
\end{array}\right]+\left[\begin{array}{c}
0.0072 \\
-0.0361 \\
0.0102
\end{array}\right]
$$

where:

$\mathrm{R}_{\mathrm{MSI}}, \mathrm{G}_{\mathrm{MSI}}, \mathrm{B}_{\mathrm{MSI}}$ have calibrated MSI bands in red, green and blue spectral bands,

$R_{i}, G_{i}$ and $B_{i}$ are spill pixels within red, green and blue spectral bands,

The coefficients for $R_{i}, G_{i}$ and $B_{i}$ are gains for red, green and blue spectral bands, and the constants in last matrix term are the offsets for red, green and blue spectral bands. 
The signature calibration matrix formulated and the related novel concept could be useful as inputs in the extraction of absolute spills signatures within the known spectral regions irrespective of satellite system used, whereas the matrices can also provide ready-ingest for rigorous computational aspects in the digital image processing of the system. The output of the calibrated and non-calibrated spill signatures in $\mathrm{B}, \mathrm{G}$, and $\mathrm{R}$ bands for selected sites as illustrated in Figure 3.
The final assessment of the calibrated signatures spills pixels in Al-khafji (Site B in Fig. 1) for significant tests for:

(i) T-test for Ho: the calibrated spill pixels treated using calibrating matrices for MSI is comparable. The comparability is to standard in-situ oil film signatures in Red, Blue and Green bands. (ii) F-test for Ho: the variation of treated spill pixels is similar to the variation of standard in-situ oil film signatures in Red, Blue and Green bands (Table 3).

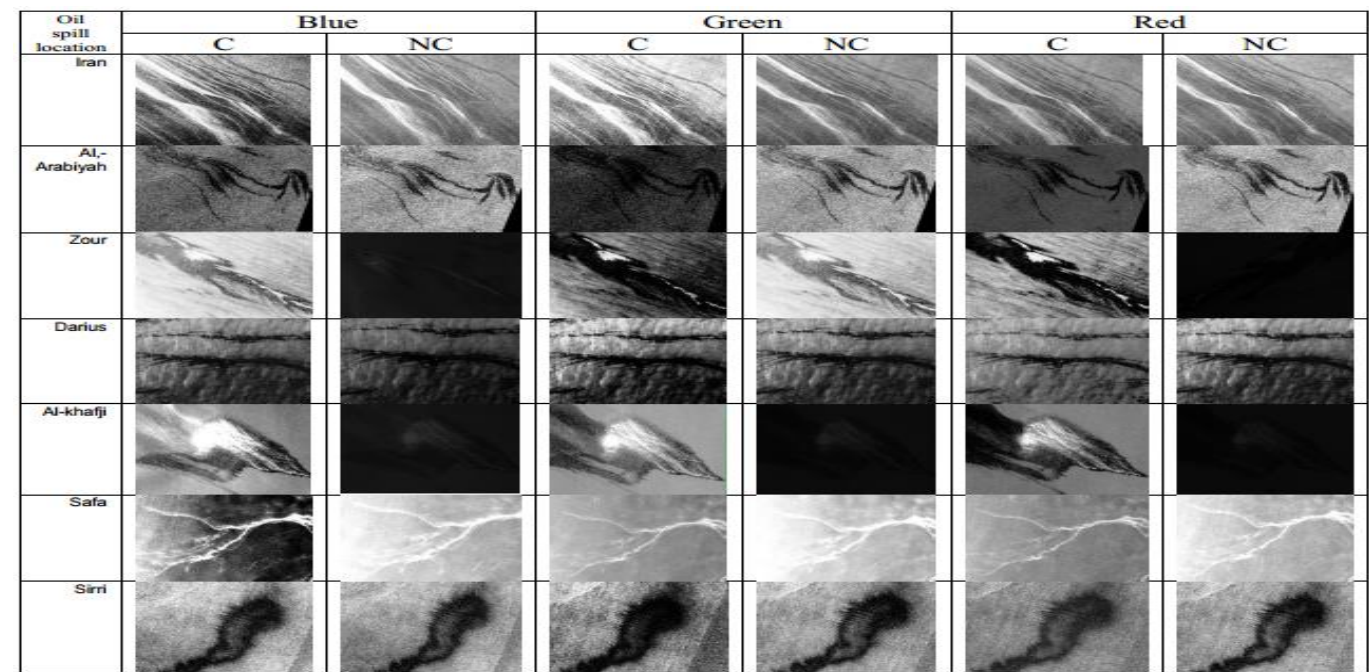

Figure 3. Output of calibrated (C) and non-calibrated (NC) spill Signatures in B, G, and R bands for selected zoomed inset of scene set of: (a) Iran, (b) al-arabiyah, (c) Zour, (d) Darius, (e) al-kahji, (f) Safa, and (g) Siri

\begin{tabular}{lllll}
\hline & t-Test & F-test & p & inference \\
\hline Sentinel-2 MSI & $1.20 \mathrm{E}-14$ & 0.011874 & 0.005 & Accept Ho \\
\hline
\end{tabular}

Table 3. Summary of spills identified based on regions grown

The results indicated acceptance of similar mean and variations to the reference oil spill spectra. Hence, this confirms the applicability of these matrices for spill signatures, calibration at absolute spectral values variations within oil spill signatures for Arabian Gulf. This event usually occurred between 2016-2017, which 7 major spill locations were highlighted.

The emphasis on these variations against the standard signature of oil film over water within visible spectral bands was reported. Similarly, this study has shown the requirements of the appropriate digital image processing and treatment to enable absolute signatures derived with calibration approach. These signature variations were used to formulate calibration matrices for spills identified from satellite images, which can be used for processing of spill monitoring system.

\section{CONCLUSIÓN}

Variations within oil spill signatures for Arabian Gulf, which occurred between 2016-2017 within 7 major spill locations, were highlighted in this study. The emphasis on these variations against the standard signature of oil film over water within visible spectral bands was reported. This study has shown the requirements of the appropriate digital image processing and treatment to enable absolute signatures derived without any uncertainties. These signature variations were used to formulate calibration matrices for spills identified from satellite images, which can be used for processing of spill monitoring system.

\section{ACKNOWLEDGEMENT}

Acknowledgements of research facilities used at Universiti Teknologi Malaysia, with grant support from supports from MOHE grants: Blue Carbon Seagrass Mapping with Remote Sensing (R.J130000.7809.4F854); and HABs Physiological Ecology. Identification using Multi-mission satellite observations (R.J130000.7809.4L851).

\section{REFERENCES}

Bhangale, U., Durbha, S. S., King, R. L., Younan, N. H. and Vatsavai, R., 2017. High-performance GPU computing-based approaches for oil spill detection from multi-temporal remote sensing data. Remote Sens. 202: 28-44.

Chenault, D. B., Vaden, J. P., Mitchell, D., and Demicco, E. D., 2016. Infrared polarimetric sensing of oil on water. Proceedings of the SPIE-The International Society for Optical Engineering, 9999.

Cheng, Y., Li, X., Xu, Q., Garcia-Pineda, O., Andersen, O. B. and Pichel, W. G., 2011. SAR observation and model tracking 
of an oil spill event in coastal waters. Marine Poll Bull. 62 (2): 350-363.

Clark, R. N., Swayze, G. A., Leifer, I., Livo, K. E., Kokaly, R., Hoefen, T., Lundeen, S., Eastwood, M., Green, R. O. and Pearson, N., 2010. A method for quantitative mapping of thick oil spills using imaging spectroscopy. USGS Open-File Report. 1167(2010): 1-51.

De Carolis, G., Adamo, M., Pasquariello, G., 2012. Thickness estimation of marine oil slicks with near-infrared meris and modis imagery: the lebanon oil spill case study. Int. Geosci. Remote Sens. Sympos. (IGARSS) 6350794, 3002-3005.

De Dominicis, M., Pinardi, N., Zodiatis, G., and Lardner, R., 2013. Medslik-II, a Lagrangian marine surface oil spill model for short-term forecasting-Part 1: Theory. Geoscience. Model Deviation. 6, 1851-1869.

Etellisi, E.A., Deng, Y., 2012. Oil spill detection: imaging system modeling and advanced image processing using optimized SDC algorithm. Signal, Image Video Proc., 1-15.

Fiscella, B., Giancaspro, A., Nirchio, F., Pavese, P. and Trivero, P., 2000. Oil spill detection using marine SAR images. Int $J$ Remote Sens. 21 (18): 3561-3566.

Gade, M., Mayer, B., Pohlmann, T., Putri, M. R.,and Setiawan, A., 2016. Using SAR data for a numerical assessment of the Indonesian coastal environment. Proc. ESA Living Planet Symposium. Prague, Czech Republic.

Garcia-Pineda, O., Holmes, J., Rissing, M., Jones, R., Wobus, C., Svejkovsky, J. and Hess, M.,2017. Detection of Oil near Shorelines during the Deepwater Horizon Oil Spill Using Synthetic Aperture Radar (SAR). Remote Sens. 9 (6): 567.

Gawad, E.A.A., Azab, M. Al., and Lotfy, M.M., 2008. Assessment of organic pollutants in coastal sediments, UAE. J. Environ. Geol. 54. 1091-1102.

Gevao, B., Beg, M.U., Al-Omair, A., Helaleh, M., and Zafar, J.,2006. Spatial distribution of polychlorinated biphenyls in coastal marine sediments receiving industrial effluents in Kuwait. Arch. Environ. Contam. Toxicol. 50. 166-17.

Guo, W.,2017. Development of a statistical oil spill model for risk assessment. Environ Pollut. 230, 945-953.

Lantzanakis, G., Mitraka, Z. and Chrysoulakis, N., 2017. Comparison of physically and image based atmospheric correction methods for Sentinel-2 satellite imagery. In Perspectives on Atmospheric Sciences pp. 255-261. Springer, Cham.

MEMAC.,2018. Oil Spill Incidents in ROPME Sea Area, Marine Emergency Mutual Aid Center, Bahrain.

Mullin, J. V., 2017. Advances from Arctic Oil Spill Response Research. Proceedings of the 2017 International Oil Spill Conference Proceedings: International Oil Spill Conference. 1487-1506.

Pinel, N., Monnier, G., Sergievskaya, I., and Bourlier, C., 2015. Simulation of infrared emissivity and reflectivity of oil films on sea surfaces. Proceedings of SPIE - The International Society for Optical Engineering, 9638.

Powers, R., Ramirez, L., Redmond, C. and Elberg, E.,1966. Geology of the Arabian Peninsula. Geological survey professional paper. 560, 1-147.

Roy, D. P., Ju, J., Lewis, P., Schaaf, C., Gao, F., Hansen, M. and Lindquist, E.,2008. Multi-temporal MODIS-Landsat data fusion for relative radiometric normalization, gap filling, and prediction of Landsat data. Remote Sens. 112 (6): 3112-3130.

Setiawan, A., Putri, M., Gade, M., Pohlmann, T., and Mayer, B., 2017. Combining ocean numerical model and SAR imagery to investigate the occurrence of oil pollution, a case study for the Java Sea. IOP Conf. Series: Earth and Environmental Science, 54.

Shih, W. C., and Andrews, A. B.,2008. Infrared contrast of crude-oil-covered water surfaces. Opt. Lett. 33, 3019-3021.

Spaulding, M. L.,2017. State of the art review and future directions in oil spill modeling. Marine Poll Bull. 115 (1-2):719.

Toming, K., Kutser, T., Laas, A., Sepp, M., Paavel, B. and Nõges, T. 2016. First experiences in mapping lake water quality parameters with Sentinel-2 MSI imagery. Remote Sens. 8 (8): 640 .

Topouzelis, K. N.,2008. Oil spill detection by SAR images: dark formation detection, feature extraction and classification algorithms. Sensors. 8 (10): 6642-6659.

Revised August 2019 